\title{
Reproducibility and validity of a questionnaire filled in by spinal cord lesioned individuals before regular follow-up
}

\author{
B Biering-Sørensen ${ }^{1}$, J Egebart ${ }^{1}$, J Hilden ${ }^{2}$ and F Biering-Sørensen ${ }^{*}, 1$ \\ ${ }^{1}$ Clinic for Para- and Tetraplegia, the Neuroscience Centre, Rigshospitalet, Copenhagen University Hospital, \\ University of Copenhagen, Denmark; ${ }^{2}$ Department of Biostatistics, University of Copenhagen, Denmark
}

\begin{abstract}
Objective: To speed up and focus (biennial) check-ups of out-patients with spinal cord lesions by means of a brief mail questionnaire concerning specific impairments as well as general life conditions.

Method: A trial 69-item questionnaire was filled in twice, at home and on arrival for checkup, and, for a third time, by the physician during the consultation. Out of 115 check-ups, 107 and 105 could be included in a reproducibility and validity assessment respectively.

Results: Excellent agreement between the first two completions ('reproducibility') and between the markings made at home and those made by the physician ('validity') was obtained for the majority of the items. Those items not performing satisfactorily, not least those relating to defecation, were scrutinised.

Conclusion: After revision, the questionnaire can serve the above mentioned purposes in a cost-effective and clinically satisfying manner. Further benefits are envisaged by computerised longitudinal monitoring of the patients' answers. Finally, we have pointed towards weak items/questions in our questionnaire, and we hope this can be of help to others who want to use similar questionnaires in their daily practice.
\end{abstract}

Spinal Cord (2001) 39, $161-167$

Keywords: questionnaire; reproducibility; validity; spinal cord injury; neurogenic bladder dysfunction; neurogenic bowel dysfunction

\section{Introduction}

Regular follow-up for spinal cord lesioned (SCL) individuals is essential because of the life-long medical and social challenges they go through. It is important to support the SCL individuals dealing with medical, functional and psychosocial problems relating to the ageing process and to life in general. ${ }^{1}$ If these problems are not discovered, are misinterpreted, or understood but not acted upon, additional impairment, disability and handicap may result. Therefore, reliable documentation of the medical problems of the SCL afflicted person is essential. ${ }^{2,3}$ A comprehensive, outpatient program offering ongoing health care for SCL individuals, has shown to be associated with increased subjective health, independence and less depression compared to those who did not receive this follow-up. Also the severity and frequency of secondary conditions, such as pressure ulcers, pain and so forth, is less for SCL individuals who receive outpatient follow-up. ${ }^{4}$

To be able to give the SCL individual the best possible follow-up we have designed a questionnaire, which is to be sent to the individual before the regular visit. Then he or she has the necessary time to go

*Correspondence: F Biering-Søresen, Clinic for Para- and Tetraplegia, Rigshospitalet, Copenhagen University Hospital, Havnevej 25, DK-3100 Hornbæk, Denmark through the various standard questions, and to come up with additional problems, which may have become relevant since the last visit to the outpatient clinic. This gives the SCL individuals the opportunity to be well prepared. Self-reported questionnaires also have other advantages, eg the asset of speed (more information within a limited time), and are therefore cost-effective. Furthermore, it is the individual's selfassessment of his or her wealth and well-being that is of greatest importance to the individual, and therefore should be of greatest importance to health care providers. ${ }^{5}$ Self-assessment focuses on personal needs and provides the patient with a maximum sense of control and involvement in the rehabilitation process. ${ }^{6}$ Additionally, a previous study has shown that patients are indeed capable of self-reporting their medical problems and physical impairments accurately. ${ }^{5}$ Still it is very important to remind ourselves that the type of information, the wording and the structure of the questionnaire, as well as the circumstances of data collection, may influence results significantly. ${ }^{7}$

Recent publications on studies including SCL participants have shown that information given on functional ability, activities of daily living, and general health-related quality of life either in questionnaires or 
interviews generally is very reliable and valid ${ }^{8-13}$ but, still, certain items of information, such as personal relationships and nutrition may show a lower reliability level. ${ }^{9}$ Therefore it is important to find out how reproducible and valid a questionnaire is, before it is adopted for routine use.

The aim of the present study was to evaluate whether a questionnaire filled in by the SCL individuals before regular follow-up is repeatable and valid; further, to provide a basis for improvement of the individual items.

\section{Material and methods}

The trial questionnaire is in Danish in its original version.

The two-page (A4 size) questionnaire includes medical, activity of daily living (ADL) and social questions. There were 51 Yes/No questions in all (Table 1), seven scaled questions (3-4 alternatives) (Table 2), and 11 questions which should be answered with a number (eg, hours) (Table 3). There are also open questions but they have not been evaluated here.

The SCL individuals were approached consecutively as they were scheduled for their routine follow-up visit to the clinic. These regular visits are made every second year. The interview and examination by the physician normally take $30-60 \mathrm{~min}$. Earlier appointments may be made if required.

A questionnaire (No.1) was mailed to the SCL individual before the regular outpatient follow-up. In an accompanying letter the individual was asked to fill in the questionnaire before the scheduled visit. The patients were not told that they would have to fill it in once more at the clinic. Upon arrival the questionnaire (No.1) was collected by the secretary, and an identical questionnaire (No.2) was handed out. The SCL individual was asked to complete it, and it was explained to him/her that it should be filled in without thinking about the previously completed questionnaire. Afterwards the secretary received this questionnaire (No.2) as well, before the physician filled in a third identical questionnaire (No.3) together with the SCL individual during the follow-up consultation. The agreement between questionnaires No. 1 and 2 was used to evaluate the 'reproducibility'. It would have been preferable to compare two rounds of mailed (or handed out) forms, but circumstances did not allow this.

Similarly, questionnaires No.1 and 3 were used for evaluation of the 'validity', in the sense of taking the results of the medical interview and examination as 'the truth'. If not the truth, this is at least a standard in the sense that it is the information on which one is going to take action and discuss the patient's future. At the end of the day, it is the best approximation to the medically relevant aspects of patient's situation. We used questionnaire No.1 for this purpose because the SCI individuals had had more time and more relaxed surroundings (their home) for the completion of the questionnaire. Also, this is how the form is to be used when adapted for routine follow-up.

\section{Confirmation frequencies}

From a practical point of view, the decisive aspect of reproducibility is to what extent a second round of interrogation would confirm the previous reply or bring forth something new. For Yes/No items we have calculated how often a Yes in the first or second questionnaire is confirmed by a Yes in the other round. Analogous confirmation frequencies have been calculated for No answers. Kappa coefficients have often been calculated in contexts like this, but they may be misleading and are difficult to interpret. ${ }^{14,15}$

\section{Results}

Out of 115 SCL individuals included in the study, 107 answered both questionnaires No.1 and 2 and could thus be included for evaluation of the reproducibility, while 105 had both questionnaire No.1 and 3 filled in and could be utilised for the validity determination.

In only 61 instances (out of 107) the date of completion for questionnaire No.1 had been filled in. It was also disappointing to observe that, for these 61 , the interval between filling in questionnaire No.1 and No.2 was highly variable and generally very short: it was on average 3.6 days (median 1 day; range $0-55$ days). Many of the SCL individuals must have waited until the same day or the day before the clinic visit before going through the questionnaire received.

Overall both reproducibility and validity were close to $100 \%$ for the majority of the items and less satisfactory for a few 'unlucky' items, the details being as follows.

For the 51 Yes/No items the percentage of identical answers regarding 'reproducibility' was on average $97.9 \%$ (SD 2.5, median 98.8, range 89.5-100), and for 'validity' $93.4 \%$ (SD 6.6, median 96.0, range $76.7-$ 100) (Table 1).

The confirmation frequencies on the right in Table 1 indicate that most negative or normal responses are trustworthy (analogous to the predictive value of a negative diagnostic test result being high), positive or abnormal ones somewhat less so (perhaps necessitating further questioning by the physician). Unsatisfactory confirmation frequencies mostly occur where already the validity column has pointed to difficulties that call for improved phrasing of the question.

For the seven scaled questions the average percentage of identical answers for 'reproducibility' was $95.3 \%$ (SD 2.7, median 94.8, range 92.3-100), and for 'validity' $90.0 \%$ (SD 6.3, median 90.8, range 82.6-98.6) (Table 2). In spite of the fact that a box check was requested in the scaled questions and an integer in the questions answered with a number, the answer was often given as an interval. In those instances the average was utilised. If the average was halfway between two integers, the category/number 
Table 1 Yes/No questions and their reproducability (frequency of agreement), validity (ie frequency of agreement with physician), and confirmation frequencies for Yes and No

\begin{tabular}{|c|c|c|c|c|c|c|}
\hline \multirow[b]{2}{*}{ Yes/No questions } & \multicolumn{2}{|c|}{ Reproducibility } & \multicolumn{2}{|c|}{ Validity } & \multirow[b]{2}{*}{$\begin{array}{l}\text { Confirmation } \\
\text { No }\end{array}$} & \multirow[b]{2}{*}{$\begin{array}{l}\text { frequency } \\
\quad \text { Yes }\end{array}$} \\
\hline & $\begin{array}{l}\text { Number of } \\
\text { answer pairs }\end{array}$ & $\begin{array}{l}\text { Per cent } \\
\text { reproducible }\end{array}$ & $\begin{array}{l}\text { Number of } \\
\text { answer pairs }\end{array}$ & $\begin{array}{l}\text { Per cent } \\
\text { validity }\end{array}$ & & \\
\hline \multicolumn{7}{|l|}{ Medical conditions } \\
\hline Other respiratory tract problems? & 89 & 98.9 & 96 & 93.8 & 99.4 & 93.3 \\
\hline Urinary tract infection? & 91 & 97.8 & 94 & 96.8 & 97.7 & 97.9 \\
\hline Other bladder/urinary system problems? & 83 & 96.4 & 89 & 77.5 & 97.8 & 88.9 \\
\hline Defecation problems? & 93 & 94.6 & 93 & 89.3 & 96.2 & 90.6 \\
\hline Pain? & 90 & 98.9 & 91 & 89.0 & 98.7 & 99.0 \\
\hline Treatment for pain? & 83 & 97.6 & 87 & 87.4 & 98.4 & 95.2 \\
\hline Skin ulcers? & 90 & 94.4 & 94 & 80.9 & 96.1 & 90.2 \\
\hline Other health problems? & 78 & 93.6 & 86 & 76.7 & 96.0 & 83.9 \\
\hline Bladder-emptying: Normal? & 101 & 97.0 & 103 & 96.1 & 98.3 & 88.0 \\
\hline Bladder-emptying: Tapping? & 101 & 99.0 & 103 & 98.1 & 99.3 & 98.4 \\
\hline Bladder-emptying: Self-catherisation? & 101 & 99.0 & 103 & 97.1 & 99.3 & 98.5 \\
\hline Bladder-emptying: Permanent catheter? & 101 & 100 & 103 & 99.0 & 100 & 100 \\
\hline Bladder-emptying: Abdominal pressure? & 101 & 98.0 & 103 & 91.3 & 98.8 & 95.0 \\
\hline Bladder-emptying: Bricker-bladder? & 101 & 100 & 103 & 100 & 100 & 100 \\
\hline Bladder-emptying: In another way? & 101 & 100 & 103 & 91.3 & 100 & 100 \\
\hline Bladder-emptying without assistance? & 87 & 98.9 & 87 & 95.4 & 94.7 & 99.4 \\
\hline Condom drainage? & 89 & 97.8 & 92 & 94.6 & 98.2 & 97.1 \\
\hline Diaper? & 89 & 97.8 & 92 & 88.0 & 98.4 & 96.3 \\
\hline Do you use something else? & 89 & 96.6 & 92 & 91.3 & 98.1 & 85.7 \\
\hline Defecation: Is normal? & 86 & 89.5 & 90 & 86.7 & 93.3 & 75.7 \\
\hline Defecation: Occurs by tapping? & 86 & 98.8 & 90 & 97.8 & 99.4 & 80.0 \\
\hline Defecation: Have to use digital evacuation? & 86 & 97.7 & 90 & 90.0 & 98.2 & 96.8 \\
\hline Defecation: Comes by itself? & 86 & 90.7 & 90 & 76.7 & 93.3 & 84.6 \\
\hline Defecation: Occurs in another way? & 86 & 89.5 & 90 & 81.1 & 92.4 & 83.0 \\
\hline Defecation: Do you use tablets laxitives? & 66 & 98.5 & 73 & 94.5 & 98.9 & 97.6 \\
\hline Do you use suppositories of other rectal laxitives? & 70 & 100 & 82 & 98.8 & 100 & 100 \\
\hline $\begin{array}{l}\text { Can you manage defecation without assistance } \\
\text { from another person? }\end{array}$ & 63 & 96.8 & 73 & 76.7 & 94.1 & 97.8 \\
\hline Average & 88.4 & 97.0 & 92.3 & 90.2 & & \\
\hline \multicolumn{7}{|l|}{ Activities of daily living } \\
\hline Do you use a standing frame? & 70 & 98.6 & 81 & 96.3 & 99.2 & 94.7 \\
\hline Can you transfer between wheelchair and bed? & 84 & 98.8 & 85 & 96.5 & 97.3 & 99.2 \\
\hline Can you transfer between wheelchair and car? & 83 & 100 & 81 & 96.3 & 100 & 100 \\
\hline Can you manage dressing by yourself? & 91 & 100 & 89 & 94.4 & 100 & 100 \\
\hline Average & 82.0 & 99.4 & 84.0 & 95.9 & & \\
\hline \multicolumn{7}{|l|}{ Social conditions } \\
\hline Housing: Room? & 69 & 98.6 & 73 & 98.6 & 99.3 & 80.0 \\
\hline Housing: Apartment? & 69 & 98.6 & 73 & 94.5 & 99.0 & 97.6 \\
\hline Housing: House? & 69 & 100 & 73 & 94.5 & 100 & 100 \\
\hline Housing: Hall of residence? & 69 & 100 & 73 & 100 & 100 & $*$ \\
\hline Housing: Protected residence? & 69 & 98.6 & 73 & 98.6 & 99.2 & 92.3 \\
\hline Housing: Nursing home? & 69 & 100 & 73 & 98.6 & 100 & 100 \\
\hline Housing: Something else? & 69 & 100 & 73 & 93.2 & 100 & 100 \\
\hline Housing: Live alone? & 90 & 98.9 & 95 & 100 & 99.0 & 98.8 \\
\hline Housing: Live together with children? & 90 & 100 & 95 & 96.8 & 100 & 100 \\
\hline Housing: Collective? & 90 & 98.9 & 95 & 100 & 99.4 & 66.7 \\
\hline Housing: Live together with spouse/partner? & 90 & 100 & 95 & 99.0 & 100 & 100 \\
\hline Housing: Live together with other family members? & 90 & 98.9 & 95 & 99.0 & 99.4 & 92.3 \\
\hline Housing: Live together with other people? & 90 & 98.9 & 95 & 97.9 & 99.4 & 80.0 \\
\hline Do you have domestic help? & 90 & 100 & 91 & 97.8 & 100 & 100 \\
\hline Do you have a visiting nurse? & 74 & 97.3 & 74 & 96.0 & 98.4 & 92.3 \\
\hline Receive pension? & 99 & 96.0 & 99 & 92.9 & 90.9 & 97.4 \\
\hline Are under education? & 99 & 100 & 99 & 99.0 & 100 & 100 \\
\hline Have paid work? & 99 & 99.0 & 99 & 98.0 & 99.3 & 98.0 \\
\hline Paid work, on full time? & 96 & 97.9 & 97 & 97.9 & 98.8 & 90.0 \\
\hline Go in for sports? & 99 & 96.0 & 99 & 92.9 & 96.8 & 94.4 \\
\hline Average & 84.0 & 98.9 & 87.0 & 97.3 & & \\
\hline Total average & 86.2 & 97.9 & 89.5 & 93.4 & & \\
\hline
\end{tabular}

*No Yes answers were given 
Table 2 Scaled questions and their reproducibilty and validity (calculated as in Table 1)

\begin{tabular}{|c|c|c|c|c|}
\hline \multirow[b]{2}{*}{ Scaled questions } & \multicolumn{2}{|c|}{ Reproducibility } & \multicolumn{2}{|c|}{ Validity } \\
\hline & $\begin{array}{l}\text { Number of } \\
\text { answer pairs }\end{array}$ & $\begin{array}{l}\text { Per cent } \\
\text { reproducible }\end{array}$ & $\begin{array}{l}\text { Number of } \\
\text { answer pairs }\end{array}$ & $\begin{array}{l}\text { Per cent } \\
\text { validity }\end{array}$ \\
\hline \multicolumn{5}{|l|}{ Medical conditions } \\
\hline $\begin{array}{l}\text { Are you incontinent between bladder-emptying } \\
\text { procedures? How often? }\end{array}$ & 73 & 94.5 & 75 & 82.7 \\
\hline How often do you have defecation? & 78 & 92.3 & 86 & 82.6 \\
\hline Average & 75.5 & 93.4 & 80.5 & 82.6 \\
\hline \multicolumn{5}{|l|}{ Activities of daily living } \\
\hline How do you most of the time get around? & 97 & 95.9 & 98 & 90.8 \\
\hline Can you manage eating by yourself? & 80 & 92.5 & 83 & 92.8 \\
\hline Has there been a change in your ADL since last visit? & 96 & 94.8 & 96 & 86.5 \\
\hline Average & 91.0 & 94.4 & 92.3 & 90.0 \\
\hline \multicolumn{5}{|l|}{ Social conditions } \\
\hline Civil status? & 70 & 97.1 & 75 & 96.0 \\
\hline Type of residence? & 77 & 100 & 72 & 98.6 \\
\hline Average & 73.5 & 98.6 & 73.5 & 97.3 \\
\hline Total average & 81.6 & 95.3 & 83.6 & 90.0 \\
\hline
\end{tabular}

Table 3 Questions answered with a number and their reproducibility and validity (calculated as in Table 1)

\begin{tabular}{|c|c|c|c|c|}
\hline \multirow[b]{2}{*}{ Questions answered with a number } & \multicolumn{2}{|c|}{ Reproducibility } & \multicolumn{2}{|c|}{ Validity } \\
\hline & $\begin{array}{l}\text { Number of } \\
\text { answer pairs }\end{array}$ & $\begin{array}{l}\text { Per cent } \\
\text { reproducibility }\end{array}$ & $\begin{array}{l}\text { Number of } \\
\text { answer pairs }\end{array}$ & $\begin{array}{l}\text { Per cent } \\
\text { validity }\end{array}$ \\
\hline \multicolumn{5}{|l|}{ Medical conditions } \\
\hline Number of admissions? & 99 & 97.0 & 97 & 90.7 \\
\hline Number of pneumonia's? & 88 & 98.9 & 95 & 99.0 \\
\hline $\begin{array}{l}\text { How many antibiotic treatments have you had for } \\
\text { urinary tract infection? }\end{array}$ & 68 & 95.6 & 71 & 87.3 \\
\hline Number of medicines? & 99 & 82.8 & 101 & 63.4 \\
\hline How many times daily do you empty your bladder? & 51 & 76.5 & 30 & 76.7 \\
\hline Average & 81.0 & 90.1 & 78.8 & 83.4 \\
\hline \multicolumn{5}{|l|}{ Activities of daily living } \\
\hline $\begin{array}{l}\text { How many hours daily do you use long leg braces in } \\
\text { average? }\end{array}$ & 100 & 96.0 & 100 & 97.0 \\
\hline How many hours daily do you use a standing frame? & 66 & 100 & 76 & 97.4 \\
\hline Average & 83.0 & 98.0 & 88.0 & 97.2 \\
\hline \multicolumn{5}{|l|}{ Social conditions } \\
\hline How many hours weekly do you have domestic help? & 82 & 95.1 & 87 & 92.0 \\
\hline How many hours weekly do you have a visiting nurse? & 69 & 97.1 & 69 & 98.6 \\
\hline $\begin{array}{l}\text { Number of hours per week in average you have paid } \\
\text { work? }\end{array}$ & 89 & 95.5 & 84 & 96.4 \\
\hline $\begin{array}{l}\text { How many hours per week in average, do you go in } \\
\text { for sports? }\end{array}$ & 92 & 90.2 & 91 & 85.7 \\
\hline Average & 83.0 & 94.5 & 82.8 & 93.2 \\
\hline Total average & 82.1 & 93.2 & 81.9 & 89.5 \\
\hline
\end{tabular}

representing the most normal situation for healthy non-paralysed individuals was used. For the 11 questions answered with a number the average percentage of strictly identical answers concerning 'reproducibility' was 93.2\% (SD 7.3, median 95.6, range $76.5-100)$, and the corresponding percentage for 'validity' was $89.5 \%$ (SD 11.0, median 92.0, range 63.4-99.0) (Table 3).

Both the 'reproducibility' and the 'validity' decrease with the number of reply alternatives, ie highest for the Yes/No questions, followed by the scaled questions and lowest for questions answered with a number.

Turning to those items that did not perform so well, we experienced for the Yes/No questions the lowest percentages for 'reproducibility' as well as 'validity' for the questions related to defecation, indicating the need for a revision of these questions. In addition, it seems that the SCL individuals and the doctor had different understandings of the questions 'other bladder/urinary system problems' 
and 'other health problems', leading to low figures for validity.

Scaled questions showed primarily problems regarding the 'validity' of the questions. In the questions 'How often are you incontinent?' and 'How often do you have defecation?' as the SCL individuals instead of using the scale often answered with an interval. The question 'changes in ADL' seems to have an inherent definition problem, in that the doctor generally demanded a larger change than the SCL person, before he/she accepted it as a change.

Among the questions answered with a number, three questions showed both the lowest "reproducibility' and 'validity': 'Kind of medicine', in particular when more than three different drugs were taken. 'How many times daily do you empty your bladder?' seemed to give problems in relation to 'voluntary emptying', and when it varied from day to day, not least depending on the fluid intake. 'How many hours per week on average, do you participate in sports', was often answered by an interval. In addition, the SCL individuals and the doctor did not always use the same definition of sports.

\section{Discussion}

Reliability refers to the reproducibility of a measure on one individual across different settings. We assessed reproducibility (reliability), ie the extent to which identical or similar questions or items give consistent responses. The test-retest procedure is probably the best way to assess the reliability of a questionnaire, and has been used in many other studies. ${ }^{16-19}$ When measuring the reproducibility by the test-retest procedure it is important that the respondents' health and condition do not change significantly in the period between the two questionnaires. Otherwise the reliability of the instrument would be underestimated. ${ }^{17,18}$ In our study this shouldn't be the case because of the very short average period between the two questionnaires. On the other hand one may claim that the reproducibility would be overestimated by the very short interval because the respondents may recall their previous answers or deliberations. Hunt et $a l^{17}$ and Wiklund et $a l^{18}$ both used an interval of 4 weeks between completion of two identical questionnaires to reduce the memory effect. In our study the patients were told to bring the first questionnaire at the followup visit, and many obviously put off filling in the questionnaire till the same day or the day before it, a feature we would have taken steps to avoid if we had foreseen it. True retesting also requires the mode of administration to be identical on the two occasions, but, as already pointed out, the present study had to settle for retesting taking place in the waiting room of the clinic.

Validity refers to the ability of an instrument to measure what actually is intended. ${ }^{20}$ Validity was assessed by comparing responses from the patient with the responses from the doctor, which were taken as 'the truth'. As already stressed, this means using the terms truth and validity in a somewhat approximate, but clinically relevant, sense. The same method was used in a study of the validity of the scaled version of the General Health Questionnaire in paralysed spinally injured outpatients. ${ }^{21}$

The 'reproducibility' and 'validity' of the questions was generally satisfactory. Some of the questions, however, may need to be changed to further improve their usefulness and reliability.

Regarding the problems of definition of various topics one could argue that these could be avoided by a standardisation, and by clarification of the medical terminology to the SCL individuals. This may be done by producing a terminology list that is sent to the SCL persons together with the questionnaire as well as used by the doctor during the interview. In 'The Stockholm spinal cord injury study' standardised operational definitions were used both for the subjects and the staff. $^{2,22}$ By such standardisations we most likely would prevent some of the disagreements between the SCL individuals and the doctors. On the other hand one may fear that many questionnaires will be left blank if there are too many things to be read.

The results showed that the reproducibility and the validity decrease with the number of reply alternatives, for which reason questions answered with a number should be interpreted with caution. ${ }^{16}$

The measurement of functional ability and social condition is increasingly important to the patient's health care and to health care research. This is because functional ability and social conditions are now recognised as an important determinant of quality of life and because functional ability correlates highly with both physical and mental health. ${ }^{4,5}$ Rehabilitation programmes aim to change behaviour in ways that support improved physical, social and psychological function, and such programmes have led to manifest changes of outcome. ${ }^{6}$ This is why the bio-psychosocial model is so important to understand and work with. $^{23}$ In our questionnaire we intend this by including questions that have to do with all three aspects.

To the ADL questions 'Can you transfer between wheelchair and bed?', 'Can you transfer between wheelchair and car?' and 'Can you manage dressing by yourself?' which should be answered with either yes or no, some SCL individuals wrote 'need some help, either by equipment or man' beside the question. These questions could be graded: 'independent', 'need extra time or equipment', 'need some help', and 'completely dependent or unable,, 5 instead of our current yes/no alternatives. Such a change may give a more specific picture of the current situation of the SCL individual, but on the other hand reduce the formal reproducibility because of more alternatives offered.

The questions 'How do you empty your bladder?' and 'How do you manage defecation?' with 'normal' as one option, were at times misinterpreted by some 
who had constant difficulties and considered this their normal (ie, usual) situation. This problem could for those contracting their injury as adults, be avoided by defining the question 'emptying by voluntary action, as before the injury'. ${ }^{2}$

The question 'Are you incontinent between bladderemptying procedures?' would probably have a higher reproducibility if we used the categories, 'often', 'seldom' and 'never', instead of 'no', 'not more than once daily' and 'more than once daily', because some patients were inclined to write a number beside the question, or to check two boxes because it varies. In this way we would see less divergence between the two questionnaires, but it would also lead to less pertinent answers. Another possibility is to ask the individual to fill in the box in accordance with the average over a fixed period. The questions 'other bladder/urinary system problems' and 'other health problems', which showed low figures especially for validity, indicate a difference in what the doctor sees as a problem as opposed to what the patient sees as a problem. Some of the problems that the SCL individual mentions in the questionnaire may be problems of no real concern to that individual. The doctor normally requires problems to be greater before accepting them as problems. However, it is important that all problems that definitely are of concern to the patient be discussed during the follow-up visit, as these may have significant influence on quality of life. This is why the patient's subjective assessment of health, disability, ADL and social condition is so important and encouraged by our questionnaire. The motivation and goals may be different and in conflict between the SCL individual and the clinician because they most likely view the medical problems differently. The aspect of what the clinician may focus on in a consultation situation, as opposed to the patient's opinion of his or her situation has further been discussed by Wiklund et $a l^{18}$ and Dunn et al. ${ }^{4}$

The intake of medicine can have an influence on reproducibility and validity because pain and other symptoms may not be a 'problem' once it is mastered with drugs but may be a great problem when the SCL individual looks back on the time before the right medicine was prescribed. ${ }^{2}$ With the large number of drugs many SCL individuals take, this ambiguity must be carefully avoided. ${ }^{24}$

The comprehensive care of patients with traumatic SCL necessitates, among other things, a structured, life-long follow-up. The high consumption of medical care in chronic SCL persons is often a result of diseases affecting many different organ systems. It soon causes the cumulated case documentation to be extensive making it hard to survey. ${ }^{25}$ This problem we try to solve by making a computer-based registry. Computerised medical records and administrative routines can among other things save both time and money. ${ }^{25,26}$

Although our questionnaire has a very large range of different questions concerning the SCL individual's health, capabilities and social conditions, the questionnaire can be made even more informative by adding more questions to the questionnaire such as: more specific questions about symptoms (eg the pain question), by adding 'mental symptoms' questions and questions about 'quality of life' as well as questions about 'sleep apnoea', 'sexual problems' and so on. A questionnaire has no limitation as to how many question can be asked, which a clinical interview will have because of limited time. On the other hand, if the questionnaire takes too much time for the patient to fill in, it may very well lead to non-compliance. Taking these things into consideration we found it suitable to make the questionnaire just two pages, with the questions we found most relevant for the follow-up. Although some SCL individuals found it necessary to write about their sexual problems in the comments space at the end of the questionnaire, other individuals might feel their privacy infringed by sexual questions, which is why we omitted them. Such items should be taken up and discussed by the doctor during the follow-up visit.

\section{Conclusion}

Follow-up by using a mailed questionnaire can be very useful both for the clinician and SCL individual because it standardises the clinical interview, has the advantage of speed, it is cost-effective and it allows the SCL individual to be well prepared for their clinical interview. The questionnaire will also show which physical or medical problems are at the moment of most importance to the SCL individual.

Our questionnaire is suitable for follow-up of all SCL individuals with no consideration of how neurological complete/incomplete the SCL is, or whether the individual has para- or tetraplegia. Further benefits are envisaged by computerised longitudinal monitoring of the SCL persons' answers.

Finally, we have pointed towards weak items/ questions in our questionnaire, and we hope this can be of help to others who want to use similar questionnaires in their daily practice.

\section{References}

1 Mattson-Prince J. A rational approach to long term care: comparing the independent living model with agency-based care for persons with high spinal cord injuries. Spinal Cord 1997; 35: $326-331$.

2 Levi R, Hultling C, Nash MS, Seiger A. The Stockholm spinal cord injury study: 1. Medical problems in a regional SCI population. Paraplegia 1995; 33: 308-315.

3 Canupp CK, Waites KB, DeVivo MJ, Richards JS. Predicting compliance with annual follow-up evaluations in persons with spinal cord injury. Spinal Cord 1997; 35: 314-319.

4 Dunn M, Love L, Ravesloot C. Subjective health in spinal cord injury after outpatient healthcare follow-up. Spinal Cord 2000; 38: $84-91$.

5 Hoenig $\mathrm{H}$ et al. The reliability of a self-reported measure of disease, impairment, and function in persons with spinal cord dysfunction. Arch Phys Med Rehabil 1998; 79: 378-387. 
6 Kennedy P, Hamilton LR. The needs assessment checklist: a clinical approach to measuring outcome. Spinal Cord 1999; 37: $136-139$.

7 Biering-Sørensen F, Hilden J. Reproducibility of the history of low-back trouble. Spine 1984; 9: 280-286.

8 Andresen EM, Fouts BS, Romeis JC, Brownson CA. Performance of health-related quality-of-life instruments in spinal cord injured population. Arch Phys Med Rehabil 1999; 80: 877-884.

9 Fougeyrollas $\mathrm{P}$ et al. Social consequences of long term impairments and disabilities: conceptual approach and assessment of handicap. Int J Rehabil Res 1998; 21: 127 - 141.

10 Hoenig $\mathrm{H}$ et al. The validity in persons with spinal cord injury of a self-reported functional measure derived from the functional independence measure. Spine 1999; 24: 539 - 543.

11 Karamehmetotglu SS et al. The functional independence measure in spinal cord injured patients: comparison of questioning with observational rating. Spinal Cord 1997; 35: $22-25$

12 Marino RJ, Shea JA, Stineman MG. The capabilities of upper extremity instrument: reliability and validity of a measure of functional limitation in Tetraplegia. Arch Phys Med Rehabil 1998; 79: $1512-1521$.

13 Post MW, de Bruin A, de Witte L, Schrijvers A. The SIP68: a measure of health-related functional status in rehabilitation medicine. Arch Phys Med Rehabil 1996; 77: 440-445.

14 Feinstein AR, Cicchette DV. High agreement but low kappa: I. The problems of two paradoxes. J Clin Epidemiol 1990; 43: $543-$ 549.

15 Cicchetti DV, Feinstein AR. High agreement but low kappa: II. Resolving the paradoxes. J Clin Epidemiol 2000; 43: 551 - 558.

16 Biering-Sørensen F, Biering-Sørensen M, Hilden J. Reproducibility of Nordic Sleep Questionnaire in spinal cord injured. Paraplegia 1994; 32: 780-786.
17 Hunt SM, McKenna SP, Williams J. Reliability of a population study tool for measuring perceived health problems. A study of patients with osteoarthrosis. Epidemiol Community Health 1981; 35: $297-300$

18 Wiklund I, Romanus B, Hunt SM. Self-assessed disability in patients with arthrosis of the hip joint. Reliability of the Swedish version of the Nottingham Health Profile. Int Disabil Studies 1988; 10: $159-163$.

19 Jenkins CD et al. A scale for the estimation of sleep problems in clinical research. J Clin Epidemiol 1988; 41: 313-321.

20 Smith HB et al. The Chronic Pain Grade questionnaire: validation and reliability in postal research. Pain 1997; 71: $141-147$.

21 Griffiths TC, Myers DH, Talbot AW. A study of the validity of the scaled version of the General Health Questionnaire in paralysed spinally injured out-patients. Psychol Med 1993; 23: $497-504$.

22 Levi R, Hultling C, Seiger A. The Stockholm Spinal Cord Injury Study: 2. Associations between clinical patient characteristics and post-acute medical problems. Paraplegia 1995; 33: 585 - 594.

23 Stoudemire A (ed). Human Behavior. An introduction for medical students. Third edition. Lippincott-Raven, Philadelphia, New York, 1998.

24 Levi R, Hultling C, Seiger $\AA$. The Stockholm Spinal Cord Injury Study. 3. Health-related issues of the Swedish annual level-of living survey in SCI subjects and controls. Paraplegia 1995; 33: $726-730$.

25 Levi R, Hultling C, Westgren N. A computer assisted follow up system for spinal cord injury patients. Paraplegia 1994; 32: $736-$ 742 .

26 Samsa G et al. Developing a national registry of veterans with spinal cord dysfunction. Spinal Cord 1998; 36: 57-62. 